\title{
Effect of haemodynamic and metabolic predictors on echocardiographic left ventricular mass in non-diabetic hypertensive patients
}

\author{
Gupta $N^{1}$, Karki P' ${ }^{1}$, Sharma $S^{1}$, Shrestha $N^{1}$, Acharya $\mathbf{P}^{1}$ \\ ${ }^{1}$ Department of Internal Medicine and Cardiology, BP Koirala Institute of Health Sciences, Dharan, Nepal
}

\begin{abstract}
Background: Left ventricular hypertrophy is a forerunner of coronary heart disease, congestive cardiac failure, stroke and may also lead to sudden death. Estimation of left ventricular mass by echocardiography offers prognostic information better than the evaluation of traditional cardiovascular risk factors.

Objective: The aim of this study was to determine the relative contributions of haemodynamic and metabolic factors affecting left ventricular mass in non-diabetic patients with essential hypertension.

Material and methods: 100 non-diabetic hypertensive patients were taken. The association between age, gender, smoking, alcohol, height, weight, heart rate, clinic blood pressure, fasting blood glucose, lipid profile, haemoglobin, body mass index and stroke volume with LV mass was studied. Left ventricular mass was measured by using standard M-mode echocardiography measurement obtained by way of standard recommended by the American Society of Echocardiography.

Results: Left ventricular mass was analyzed as a continuous variable. In males body mass index $(\mathrm{r}=.35$, $\mathrm{p}<.004)$ and stroke volume $(r=-.26, p<.039)$ were significantly correlated with LV mass. In females body weight was significantly related to left ventricular mass $(\mathrm{r}=.36, \mathrm{p}<.02)$. The independent association between significant factors and left ventricular mass was assessed by stepwise multivariate logistic regression. Body mass index and systolic blood pressure came as independent determinants of left ventricular mass in all patients. A maximum of $13 \%$ of left ventricular mass variability could be explained by these two factors.

Conclusion: In untreated patients with hypertension patient's body mass index and systolic blood pressure are independent predictors of left ventricular mass after adjustment for other haemodynamic and metabolic factors. They explain a maximum of $13 \%$ of left ventricular mass variability. More knowledge is needed about factors that may alter cardiac morphology in the evolution of hypertensive patients.
\end{abstract}

Key words: Echocardiography, Haemodynamic, Metabolic Factors, Left Ventricular Mass, Non-diabetic, Hypertensive

$\mathrm{M}$ ost common effect of hypertension on the heart is hypertrophy of left ventricle. Left ventricular hypertrophy is a forerunner of coronary heart disease, congestive cardiac failure, stroke and may also lead to sudden death ${ }^{1-3}$. Increased LV mass and hypertrophy on the echocardiogram are associated with increased risk for sudden death after accounting for other known coronary disease risk factors ${ }^{3}$. Estimation of left ventricular mass by echocardiography offers prognostic information beyond that provided by the evaluation of traditional cardiovascular risk factors. In men, the risk factor-adjusted relative risk of cardiovascular disease was 1.49 for each increment of $50 \mathrm{~g} / \mathrm{m}$ in left ventricular mass corrected for the subject's height, in women it was $1.57^{4}$.

Left ventricular (LV) mass has been known to be determined by sex, age, height, weight, obesity, alcohol use, stroke volume and blood pressure ${ }^{5-7} .24$ hour ambulatory blood pressure explains the variability of LV mass better than clinic BP and can assess day night BP variability which is of interest because lack of nocturnal B.P. fall has been associated with increased left ventricular mass ${ }^{8,9}$. Body size is a powerful determinant of LV mass and it may explain part of sex difference in LV mass ${ }^{10}$. Weight reduction has been shown to decrease left ventricular mass index in overweight hypertensive patients even more than pharmacological anti hypertensive treatment ${ }^{11}$. Several non haemodynamic determinants of LV mass have also been described like angiotensin II, catecholamine, hyperinsulinaemia and insulin resistance ${ }^{12,13}$. Dyslipidemia is another metabolic abnormality observed most frequently in hypertensive

Correspondence

Dr. Prahlad Karki

Professor and Head,

Department of Internal Medicine \& Cardiology Division

E-mail: prahladkarki@hotmail.com 
patients. A positive association between total and low density lipoprotein cholesterol and coronary heart disease is well established ${ }^{14,15}$. However, the existence of independent association between serum lipids and LV mass is not clear.

So, the present study was done to evaluate haemodynamic and metabolic predictors of LV mass moresoever because there is lack of data regarding similar, studies in South Asian countries especially in Nepal.

\section{Materials and methods}

\section{Study population}

Study population consisted of consecutive patients with hypertension attending medical OPD in B.P. Koirala Institute of Health Sciences, Dharan (BPKIHS), until a sample size of 100 was attained. Study duration consisted of one year from $1^{\text {st }}$ June 2004 to $31^{\text {st }}$ may 2005.

\section{Study population was first screened by}

- Fasting blood sugar

- Blood Pressure measurement

Clinic blood pressure was measured by a physician in the hospital outpatient clinic with a mercury sphygmomanometer after the subject sat for about 5 minutes. Two readings 5 minutes apart on at least two separate visits were taken. An average of the 4 measurements was considered for analysis. Hypertension was diagnosed if the average reading was 140/90 mm Hg or more. Diabetes was diagnosed as either symptoms of diabetes plus random plasma glucose concentration > equal to $200 \mathrm{mg} / \mathrm{dl}$ or fasting plasma glucose $>$ equal to $126 \mathrm{mg} / \mathrm{dl}^{16}$.

All subjects fulfilling the following criteria were included: (1) Non-diabetic patients with blood pressure of 140/90 mm Hg or more; (2) No previous treatment with anti hypertensive drugs or less than 3 weeks treatment at any time ${ }^{17}$; (3) No previous treatment with lipid lowering drugs.

Then out of these, patients having following criteria were excluded.(1) Age <30 years;(2) Haemodyanamically unstable patients;(3) Heart failure;(4) Regional wall motion abnormality;(5) Hypertrophic cardiomyopathy;(6) Ventricular aneurysm;(7) Significant stenotic or regurgitant valvular defects(8) Poor cardioecho window. Patients fulfilling all the inclusion criteria and not having any of the exclusion criteria were included in the study.

Following variables were studied in them with the help of a performa and investigations. Age, gender, smoking (in pack years), alcohol (amount/day, duration), body height, body weight, heart rate, clinic blood pressure, fasting blood glucose, lipid profile(After 14 hour of fasting), Total cholesterol, HDL cholesterol, Triglycerides, LDL cholesterol, haemoglobin, body mass index (Weight/height ${ }^{2}$ ), Stroke volume (SV).

Echocardiographic Examination:

An M-mode echocardiography study (Hewlett Packard Sonos1800) was performed under two dimensional control. Measurements of left ventricular internal diameter and septal and posterior wall thickness were taken at end diastole according to the American Society of Echocardiography ${ }^{18}$. Left Ventricular Mass (LVM) was calculated using Devereux formula ${ }^{19}$.

LVM=1.04 (LVIDd + IVSTd + LVPWTd $)^{3}-(\text { LVIDd })^{3}$ $-13.6 \mathrm{gms}$.

Because left ventricular mass varies directly with the body surface Area, it was commonly indexed for this measure of body size. This was left ventricular mass index (LVMI) expressed in gram/square meter.

LVMI $\left(\mathrm{gram} / \mathrm{m}^{2}\right)=\mathrm{LVM} / \mathrm{BSA}$. Left ventricular outflow tract diameter (D) and timed velocity integral (TVI) were also measured.

Stroke volume was calculated by the formula SV $=\mathrm{D}^{2 *} .785 * \mathrm{TVI}$.

\section{Statistical analysis}

Data were recorded on a pre-design Performa and managed on an excel spread sheet. Quantitative variables were summarized by mean \pm S.D. Median was calculated for variables having wide range of values.

Pearson correlation coefficient (r) was between two quantitative variable following normal distribution was calculated.

For variable following non-normal distribution spearman's rank correlation (rho) was calculated.

Multiple variate linear regression analysis was applied to determine the predictors of left ventricular mass.

Strata 8.0 were used for statistical analysis.

In this study $\mathrm{p}$ value $<0.05$ has been considered statistically significant.

Results

One hundred and ten patients of essential hypertension were screened and out of those 10 were excluded, one due to age $<30$, two due to significant stenotic or regurgitant defects and seven due to poor cardio echo 
window. In 100 patients analysis was done. Out of these 62 were males and 38 were females.

Table 2 shows the mean values of Left Ventricular Internal Dimension in the diastole (LVIDd), Left Ventricular Posterior Wall Thickness in diastole (LVPWTd), Inter Septal Thickness in diastole (IVSTd) in study subjects.

The mean left ventricular mass and left ventricular mass index in age greater than 40 was $214.16 \pm 90.57$ $(\mathrm{gm})$ and $130.82 \pm 54.30\left(\mathrm{gm} / \mathrm{m}^{2}\right)$ respectively and in age less than 40 was $164.58 \pm 58.7(\mathrm{gm})$ and $97.08 \pm$ $28.20\left(\mathrm{gm} / \mathrm{m}^{2}\right)$ respectively. The $\mathrm{p}$-value for difference in LVM was 0.05 and LVMI was 0.03 , which were significant in our study. The left ventricular mass and left ventricular mass index was studied by dividing the study population in sub category of body mass index less than or greater than 25.The left ventricular mass in BMI $>25$ was $236.15 \pm 110.54(\mathrm{gm})$ and in $<25$ was $188.76(\mathrm{gm})$ and the difference was significant.

\section{Univariate analysis}

Left ventricular mass was analyzed as a continuous variable. The association of variables with left ventricular mass was separately assessed in males and females. In males Body mass index was strongly positively related with left ventricular mass $(\mathrm{r}=.35, \mathrm{p}<.004)$ and stroke volume was inversely related with left ventricular mass $(\mathrm{r}=-.26, \mathrm{p}<.039)$
In females body weight was significantly positively related to left ventricular mass $(r=.36, \mathrm{p}<.02)$.

In all patients body weight $(\mathrm{p}=0.005)$ and body mass index $(p=0.003)$ had a significant direct association with left ventricular mass. And pack years of smoking were weakly inversely related to left ventricular mass (p-value <.15). Systolic blood pressure, pulse pressure, Age, height, diastolic blood pressure, fasting blood sugar and haemoglobin had a positive correlation with left ventricular mass but the correlation was not significant. Stroke volume, heart rate, total cholesterol, high density lipoprotein cholesterol, low density lipoprotein cholesterol had an inverse association with left ventricular mass but the correlation was not significant. (Table 3)

Number of pack years, duration and amount of alcohol were not significantly correlated with left ventricular mass in all patients.

The independent association between significant factors and left ventricular mass was assessed by stepwise multivariate logistic regression. Body mass index and systolic blood pressure came as independent determinants of left ventricular mass in all patients in our study. A maximum of $13 \%$ of left ventricular mass variability could be explained by these two factors. (Table 4).

Table 1: Baseline characteristics of the 100 patients according to gender

\begin{tabular}{|l|c|c|c|}
\hline Variables & All(N=100) & Men(N=62) & Women(N=38) \\
\hline Age(yrs) & $53 \pm 12.4$ & $52.6 \pm 12.78$ & $53.6 \pm 11.9$ \\
\hline Pack year & $15(1-50)$ & $15(1-50)$ & $10(3-35)$ \\
\hline Alcohol (duration in years) & $20(5-60)$ & $20(10-60)$ & $22.5(5-50)$ \\
\hline Alcohol(amount ml/day) & $500(50-1000)$ & $500(50-1000)$ & $500(200-1000)$ \\
\hline Ht(cm) & $156.02 \pm 18.2$ & $160.12 \pm 21.5$ & $54.3 \pm 7.07$ \\
\hline Wt(kg) & $60.8 \pm 10.1$ & $64.65 \pm 8.8$ & $24.5 \pm 4.05$ \\
\hline BMI $\left(\mathrm{kg} / \mathrm{m}^{2}\right)$ & $24.4 \pm 3.4$ & $24.3 \pm 2.9$ & $150.8 \pm 17.09$ \\
\hline SBP(mm hg) & $152.6 \pm 16.09$ & $153.7 \pm 15.5$ & $98.5 \pm 7.8$ \\
\hline DBP(mm hg) & $100.4 \pm 8.27$ & $101.5 \pm 8.4$ & $52.3 \pm 16.08$ \\
\hline PP & $52.04 \pm 14.45$ & $51.8 \pm 13.4$ & $84.3 \pm 10.76$ \\
\hline HR $(/ \mathrm{min})$ & $85.3 \pm 12.7$ & $85.9 \pm 13.8$ & $169.5 \pm 38.9$ \\
\hline TC(mg/dl) & $168.7 \pm 34.0$ & $168.2 \pm 30.9$ & $44.2 \pm 8.7$ \\
\hline HDL $(\mathrm{mg} / \mathrm{dl})$ & $43.2 \pm 8.85$ & $42.6 \pm 8.9$ & $136.08 \pm 74.6$ \\
\hline TGA(mg/dl) & $152.8 \pm 83.66$ & $163.1 \pm 87.72$ & $99.5 \pm 38.5$ \\
\hline LDL(mg/dl) & $95.1 \pm 32.55$ & $92.4 \pm 28.2$ & $81.05 \pm 11.9$ \\
\hline FBS(mg/dl) & $83.68 \pm 14.3$ & $85.2 \pm 15.5$ & $13.36 \pm 1.2$ \\
\hline Hb $(\mathrm{g} / \mathrm{ml})$ & $13.92 \pm 1.34$ & $14.2 \pm 1.02$ & $53.95 \pm 22.5$ \\
\hline SV(ml) & $59.67 \pm 25.57$ & $63.1 \pm 26.8$ & $195.7 \pm 110.5$ \\
\hline LVM $(\mathrm{gm})$ & $207.7 \pm 88.46$ & $215.03 \pm 71.6$ & $126.3 \pm 65.8$ \\
\hline LVMI(gm/m & $126.4 \pm 52.8$ & $126.4 \pm 43.5$ & \\
\hline
\end{tabular}


Table 2: Echocardiographic findings according to gender

\begin{tabular}{|l|c|c|c|}
\hline & All $(\mathbf{N}=\mathbf{1 0 0})$ & Males $(\mathbf{N}=\mathbf{6 2})$ & Females $(\mathbf{N}=\mathbf{3 8})$ \\
\hline IVSTd $(\mathrm{cm})$ & $1.13 \pm 0.24$ & $1.15 \pm 0.22$ & $1.09 \pm 0.27$ \\
\hline LVIDd $(\mathrm{cm})$ & $4.41 \pm 0.66$ & $4.47 \pm 0.67$ & $4.31 \pm 0.63$ \\
\hline LVPWTd $(\mathrm{cm})$ & $1.05 \pm 0.26$ & $1.08 \pm 0.25$ & $1.01 \pm 0.26$ \\
\hline
\end{tabular}

* Values are expressed in mean+S.D.

Table 3: Pearson's bivariate correlation coefficient of left ventricular mass with selected parameters in all patients $(n=100)$

\begin{tabular}{|l|c|c|}
\hline Variables & Pearson's correlation & p-value \\
\hline Age & .123 & .221 \\
\hline $\mathrm{Ht}$ & .062 & .537 \\
\hline $\mathrm{Wt}$ & .280 & $\mathbf{. 0 0 5}^{* *}$ \\
\hline $\mathrm{BMI}$ & .293 &. $\mathbf{. 0 0 3}^{* *}$ \\
\hline SBP & .189 & .06 \\
\hline DBP & .086 & .39 \\
\hline PP & .168 & .09 \\
\hline HR & -.059 & .56 \\
\hline TC & -.107 & .29 \\
\hline HDL & -.088 & .38 \\
\hline TGA & .036 & .72 \\
\hline LDL & -.118 & .24 \\
\hline FBS & .041 & .68 \\
\hline Hb & .094 & .35 \\
\hline SV & -.15 & .12 \\
\hline
\end{tabular}

** Correlation significant at $\mathrm{p}<.05$ level

Table 4: Results of bivariate and stepwise multivariate regression analysis

\begin{tabular}{|l|c|c|c|c|c|c|}
\hline Variables & \multicolumn{2}{|c|}{ Unadjusted regression coefficient $\mathbf{( 9 5 \%}$ CI) } & \multicolumn{3}{|c|}{ Adjusted regression coefficient(95\% CI) } \\
\hline & Beta & $\mathbf{9 5 \%}$ CI & p-value & Beta & $\mathbf{9 5 \%}$ CI & p-value \\
\hline BMI & 7.6 & $(2.6,12.5)$ & 0.003 & 7.8 & $(3.0,12.7)$ & 0.002 \\
\hline SBP & 1.0 & $(-0.4,2.12)$ & 0.06 & 1.1 & $(0.09,2.16)$ & 0.03 \\
\hline PP & 1.03 & $(-0.18,2.23)$ & 0.09 & - & - & - \\
\hline SV & -0.54 & $(-1.2,0.14)$ & 0.12 & - & - & - \\
\hline
\end{tabular}

R Square (coefficient of determination $)=13 \%$

\section{Discussion}

Previous studies have shown greater left ventricular mass in men than woman ${ }^{20,21,22}$. However it is uncertain whether these differences in left ventricular mass represent an independent effect of gender or due to greater lean body weight in men accounting for greater left ventricular mass in men than in women ${ }^{21}$. Overall, the effect of gender on left ventricle mass seems to be minor taking total body weight into account ${ }^{20,21,23}$. In our study,mean left ventricular mass in men was greater than woman (215.03 \pm 71.6 and $195.7 \pm 110.5$ respectively). But mean left ventricular mass index was almost equal in both sexes confirming the hypothesis that difference in left ventricular is more due to difference in height and weight in males and females. Armario et al and Devereux et $\mathrm{al}^{7,24}$ showed that that the difference in the mean left ventricular mass and left ventricular mass index when divided according to age group was not significant and neither age was a significant determinant of left ventricular mass.But Schillaci et $\mathrm{al}^{5}$ showed that age was a potential determinant of left ventricular mass in women and men. In our study the difference between mean of left ventricular mass and left ventricular mass index when divided by age less than or greater than 40 was significant $(\mathrm{p}<.05)$ but the correlation of age with left ventricular mass was not significant.The possible cause of significant difference found in left ventricular 
mass and left ventricular mass index when divided by age category was may be due to large difference in number of subjects in both group, 87 in age $>40$ and only 13 in age less than equal to 40 .

Left ventricular mass and left ventricular mass index were greater in subjects with greater body mass index and with multiple linear regression analysis body mass index came as an independent predictor of left ventricular mass in our study. This result was similar with previous studies ${ }^{5,24}$.

Previous studies have shown both office blood pressure and average 24 hour blood pressure to be significantly correlated with left ventricular mass ${ }^{5,7,24}$. Correlation coefficient for 24 hour blood pressure is found to be higher than office blood pressure ${ }^{5}$. In our study left ventricular mass and left ventricular mass index increased with increasing clinic systolic and diastolic blood pressure. Systolic blood pressure correlated significantly with left ventricular mass in univariate analysis and was an independent predictor of left ventricular mass in multivariate regression analysis. However clinic diastolic blood pressure was not significantly associated with left ventricular mass. We did not look for the correlation of average 24 hour blood pressure with left ventricular mass in this study.

In summary, various previous studies have shown height, weight, body mass index, office and 24 hour blood pressure, stroke volume, heart rate, high density cholesterol, low density cholesterol, total cholesterol to be independent predictors of left ventricular mass and these factors could explain left ventricular mass variability ranging from $21 \%$ to $48 \%$ in different studies $5,7,24,22$. Our study showed body mass index and clinic systolic blood pressure to be independent predictors of left ventricular mass and could explain $13 \%$ of left ventricular mass variability. This difference in result could be due to difference in number of study population. Maximum of the studies had study population ranging from 1200 to 1800 . In our study subjects were only 100 .

Various other factors like insulin resistance, subscapular skin fold thickness, cardiac contractility, aortic root diameter, plasma epinephrine, urinary sodium excretion are found to be determinants of left ventricular mass $^{7,25,22,26,27}$. We could not study these variables in this study.

\section{Limitations}

The sample size in this study was small which could be a reason that we got only two factors as independent determinants of left ventricular mass in multivariate regression analysis twenty four hour blood pressure has been found to be more significantly correlated with left ventricular mass than office blood pressure, which could not be done in this study.

\section{Conclusion}

In untreated patients with hypertension patient's body mass index and systolic blood pressure are independent predictors of left ventricular mass after adjustment for other haemodynamic and metabolic factors. They explain a maximum of $13 \%$ of left ventricular mass variability. More knowledge is needed about factors that may alter cardiac morphology in the evolution of hypertensive patients.

\section{References}

1. Kannel WB, Levy D, Cupples LA. Left ventricular hypertrophy and risk of cardiac failure: insights from the Framingham study. J Cardiovascular Pharmacol. 1987;40(1):71-80.

2. Mc Gee DL, Savage D. A model for comparison of Left Ventricular Mass and Systolic Blood Pressure as risk factors for stroke. Clin Cardiol. 1989;4:30 -3.

3. Haider AW, Larson MG, Benjamin EJ, Levy D. Increased Left Ventricular Mass and Hypertrophy are associated with increased risk for sudden death. J Am Coll Cardiol. 1998;32(5):1454 - 9.

4. Levy D, Garrison RJ, Savage DD, Kannel WB, Castelli WP. Prognostic implication of echocardiographically determined left ventricular mass in the Framingham heart study. N Eng J Med. 1990;322:1561-6.

5. Schillaci G, Vaudo G, Reboldi G, Verdecchia P, Lupattelli G, Pasqualini L, et al. High density lipoprotein cholesterol and left ventricular hypertrophy in essential hypertension. J Hypertension. 2001; 19:2265-70.

6. Sundstrom J, Lind L, Vessby B, Andren B, Aro A, Lithell HO. Dyslipidemia and an unfavorable fatty acid profile predict left ventricular hypertrophy 20 years later. Circulation.2001;103:836-41.

7. Armario P, Del Rey RH, Sanchez P, MartinBaranera M, Torres G, Julia J, et al.. Determinants of left ventricular mass in untreated mildly hypertensive subjects. Am J Hypertens. 1999; 12:1084-90.

8. Verdecchia P, Schilloci G, Guerrieri M, Gotteschi C, Benemia G, Boldrini F, et al. Circadian blood pressure changes and left ventricular hypertrophy in hypertension. Circulation. 1990;81:528-36.

9. Rizzoni D, Mujesan ML, Montani G, Zulli R, Celebich S, Agabiti-Rosei E. Relationship 
between initial cardiovascular structural changes and day-time and night time blood pressure monitoring. Am J Hypertens. 1992;5:180-6.

10. De Simone G, Devereux RB, Daniels SR, Meyer RA. Gender differences in left ventricular growth. Hypertension 1995;26:979-83.

11. Mac Mohan SW, Wilcken DE, Macdonald GJ. The effect of weight reduction on left ventricular mass: a randomized controlled trial in young overweight hypertensive patients. N Eng J Med. 1986;314:334-9.

12. Watanabe K, Sekiya M, Tsuruoka T, Funada J, Kameoka H. Effect of insulin resistance on left ventricular hypertrophy and dysfunction in essential hypertension. J Hypertens. 1999;17(8):1153-60.

13. Palatini P, Majahalme S, Amerena J, Nesbitt S, Vriz O, Michieletto M, et al. Determinants of left ventricular structure and mass in young subjects with sympathetic over-activity. The Tecumseh Offspring Study. J Hypertens. 2000;18:1311-6.

14. Gordon DJ, Rifkind BM. High density lipoprotein -the clinical implication of recent studies. N Eng J Med. 1989;321:1311-6.

15. Manninen V, Tenkonen L, Koskinen P, Huttunen JK, Manttari M, et al. Joint effects of serum triglyceride and LDL cholesterol and HDL cholesterol concentrations on coronary heart disease risk in the Helsinki heart study, implications for treatment. Circulation. 1992;85:37-45.

16. American diabetes Association. Clinical Practice Recommendations 2003. USA: American diabetes Association; 2003.

17. Frohilch E. Hypertension: evaluation and management.

18. Feigenbaum H. Echocardiography. 5th edition. Philadelphia, Pa: Lea \& Febiger; 1994. p. 65860 .
19. Devereux RB, Reichek N. Echocardiographic determination of Left Ventricular Mass in man: Anatomic validation of the method. Circulation. 1977;55:613 - 8.

20. Gardin J, Savage D, Ware J, Henry W. Effect of age, sex and body surface area on echocardigraphic left ventricular mass in normal subjects. Hypertension. 1987; 9: II-36-II-39.

21. Hammond IW, Devereux RB, Alderman MH, Laragh JH. Relation of blood pressure and body build to left ventricular mass in normotensive and hypertensive employed adults. J Am Coll Cardiol. 1988;12:996-1004.

22. Roy M, Lisa K, Alan BW, Agnes D, Nicholas JS, Stevo J. Sex-Specific Determinants of Increased Left Ventricular Mass in the Tecumseh blood Pressure Study. Circulation. 1994;90(2):928-36.

23. Kupari M, Koskinen P, Virilainer J. Corelates of left ventricular mass in a population sample aged 36 to 37 years. Focus on lifestyle and salt intake. Circulation. 1994;89:1041-50.

24. Devereux RB, Roman MJ, De Simone G, O'Grady MJ, Paranicas M, Yeh J, et al. Relations of Left Ventricular Mass to Demographic and Hemodynamic Variables in American Indians. Circulation. 1997;96:1416-23.

25. Gardin JM, Wagenknecht LE, Anton-Culver H, Flack J, Gidding S, Kurosaki T, et al. Relationship of Cardiovascular Risk Factors to Echocardiographic Left Ventricular Mass in Healthy Young Black and White Adult Men and Women. Circulation. 1995;92:380-7.

26. Chen C, Ting C, Lin S, Hsu T, Ho S, Chou P, et al. Which Arterial and Cardiac Parameters Best Predict Left Ventricular Mass. Circulation. 1998;98:422-8.

27. Zion S, Yosef R, Teosar B, Iris R. Cardiovascular risk factors, lipids, and insulin: Insulin resistance is an important determinant of left ventricular mass in the obese. Circulation. 1993;88(4):1431-6. 